Portland State University

PDXScholar

1989

\title{
The interaction of stimulus rate and polarity effects on the auditory brainstem response
}

Michelle Ann Nielsen Ziegler

Portland State University

Follow this and additional works at: https://pdxscholar.library.pdx.edu/open_access_etds

Part of the Speech and Hearing Science Commons

Let us know how access to this document benefits you.

\section{Recommended Citation}

Ziegler, Michelle Ann Nielsen, "The interaction of stimulus rate and polarity effects on the auditory brainstem response" (1989). Dissertations and Theses. Paper 3957.

https://doi.org/10.15760/etd.5841

This Thesis is brought to you for free and open access. It has been accepted for inclusion in Dissertations and Theses by an authorized administrator of PDXScholar. Please contact us if we can make this document more accessible: pdxscholar@pdx.edu. 
AN ABSTRACT OF THE THESIS OF Michelle Ann Nielsen Ziegler for the Master of Science in Speech Communication: Speech and Hearing Sciences presented May 3, 1989.

Title: The Interaction of Stimulus Rate and Polarity Effects on the Auditory Brainstem Response.

APPROVED BY THE MEMBERS OF THE THESIS COMMITTEE:

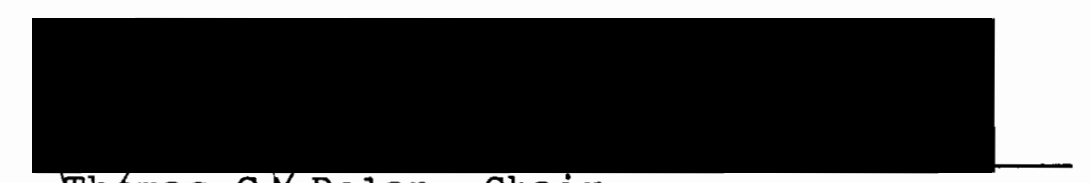

Thomas G: Dolan, Chair
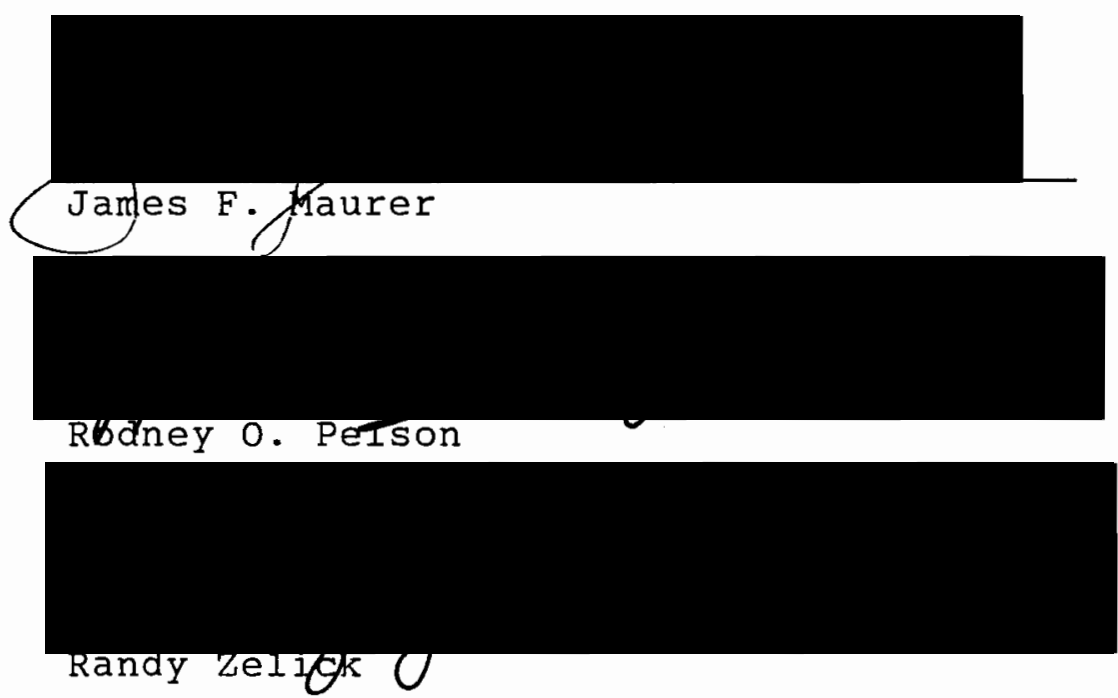

Research on the Auditory Brainstem Response (ABR) has been dominated by attempts to develop techniques to enhance the clarity of the ABR waveform and to define the parameters that separate normal from abnormal responses. While the effects of stimulus rate are clearly documented, the effects of stimulus polarity on the ABR are not. There may be an 
interaction of polarity and rate which accounts for the inconsistent results reported in the literature.

This study examined the effect of stimulus rate and polarity for waves I, III, and V, on the ABR latency, amplitude, and amplitude ratio. Rarefaction and condensation clicks were delivered at rates of $11.1 ; 21.1,41.1$, and 81.1 clicks per second. Fourteen male subjects were used, each having normal hearing thresholds and normal middle ear function.

The results from this investigation revealed no interaction of rate and polarity on the three waves under study. There was a significant rate effect but not a significant polarity effect for latency, amplitude, and amplitude ratio.

These results reveal that the discrepant results in the literature are not due to the different stimulus rates. Therefore, further investigation on the effects of polarity is recommended. 
THE INTERACTION OF STIMULUS RATE AND POLARITY EFFECTS ON THE AUDITORY BRAINSTEM RESPONSE

by

MICHELLE ANN NIELSEN ZIEGLER

A thesis submitted in partial fulfillment of the requirements for the degree of

\author{
MASTER OF SCIENCE \\ in \\ SPEECH COMMUNICATION : \\ SPEECH AND HEARING SCIENCES
}

Portland State University

1989 
TO THE OFFICE OF GRADUATE STUDIES:

The members of the Committee approve the thesis of Michelle Ann Nielsen Ziegler presented May 3, 1989.

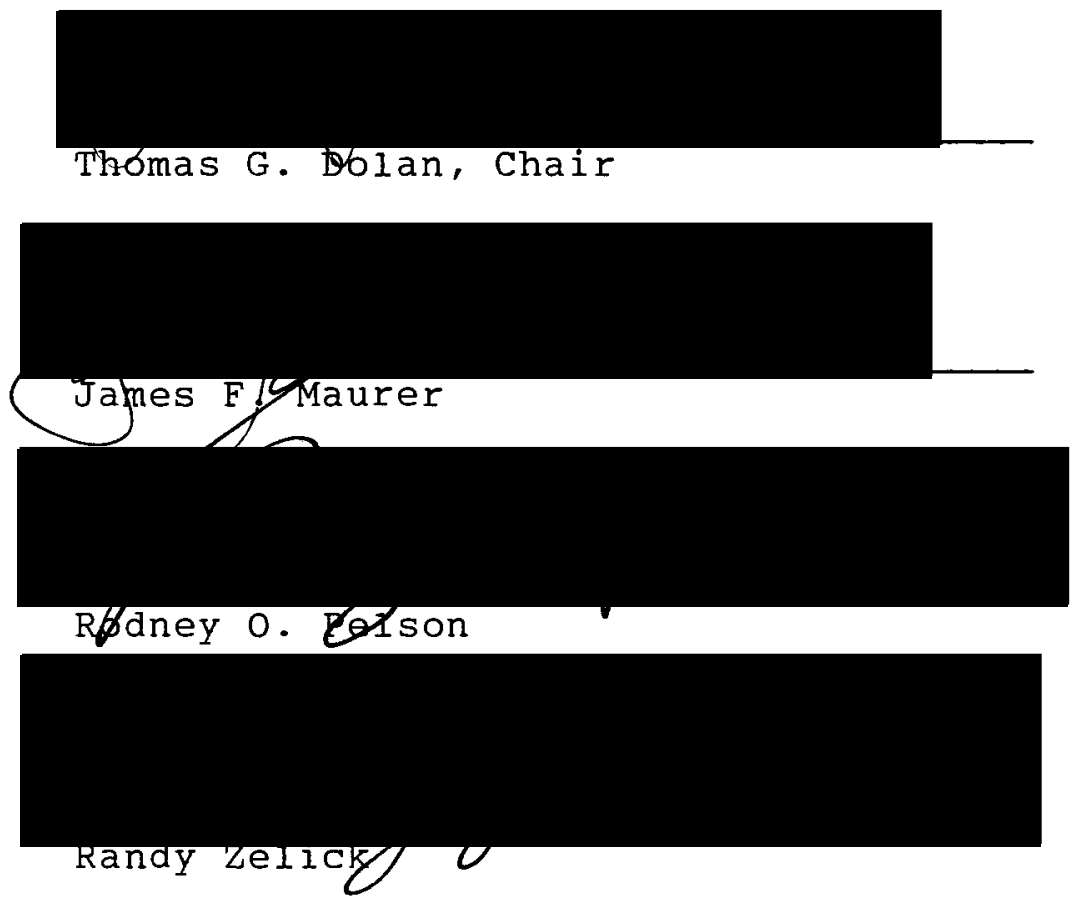

APPROVED :

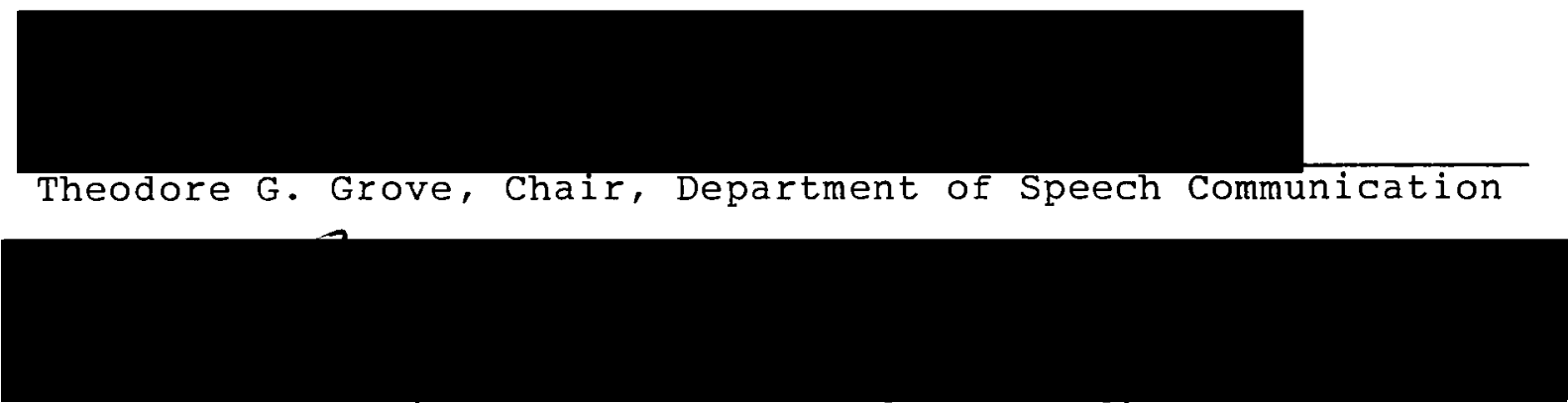

Bernard Ross, Vice Provost for Graduate Studies 
- Dedicated in loving memory to John Nielsen - 


\section{ACKNOWLEDGMENTS}

A thesis requires considerable effort from a great number of people. Therefore, I wish to express my sincere thanks to the following individuals for their effort on my behalf:

Thomas Dolan, for his direction of this project. James F. Maurer, for his valuable input; and Rodney Pelson, for his patience, understanding, and guidance during the three years this thesis took to complete.

My friend, Jill Trestik, who never doubted that this project would be completed; Brent McMulin, who always listened and encouraged me; and Sheila Runcie, whose loving care of my children gave me the peace of mind needed to concentrate on my writing.

My family provided considerable support and encouragement during this thesis project. I thank my parents, Jerry and Joyce Nielsen, and my in-laws, Jack and Jean Ziegler for their love and support. A very special thank you to my husband, Steve; and my daughters, Jennifer and Molly for their understanding and patience while I worked on my thesis instead of reading stories and playing dolls. Now, Jenny, my "homework" is done.

This thesis is dedicated to the memory of my paternal grandfather, John Nielsen, an immigrant from Denmark in the 
1920's. He inspired me to set goals and achieve those goals. He believed in higher education and desired all of his grandchildren to achieve a college education. He died just after my graduate coursework was completed in 1986. His wish was that I complete my Masters degree. Because of that wish I have kept working on this thesis even though there were many times I would have liked to have given up. His wish has now been fulfilled. 
TABLE OF CONTENTS

PAGE

ACKNOWLEDGMENTS . • . . . . . . . . . . . . . . . . . . . iv

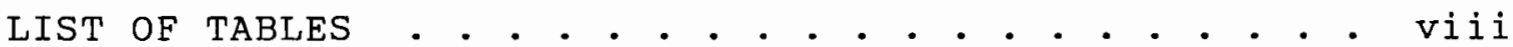

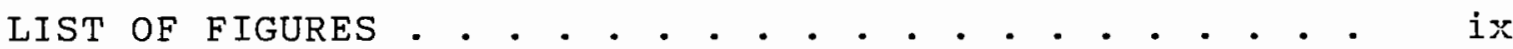

CHAPTER

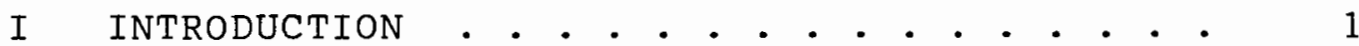

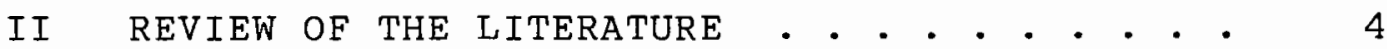

Criteria for ABR Interpretation . . . . . 6

The Effects of Stimulus Rate on the ABR . 7

Latency

Amplitude

Interpeak Latency

Waveform Morphology

The Effects of Stimulus Polarity on

the ABR . . . . . . . . . . . . 10

Latency

Amplitude and Waveform

Interpeak Latency

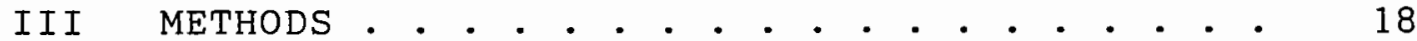

Subjects . • . • . . . . . . . . 18

Procedures . . . . . . . . . . . . . . 19

IV RESULTS . • . . . . . . . . • . . . . . . 21

Test-Retest Reliability . . . . . . . . 21

Amplitude . . . . . . . . . . . . . 23

Latency • . • . • . . . . . • . • • 28

Amplitude Ratio V/I . . . . . . . . 32 
CHAPTER

V DISCUSSION . . . . . . . . . . . . . . . 35

REFERENCES . . . . . . . . . . . . . . . . . . . . . . 38 APPENDICES

A INTAKE INFORMATION . . . . . . . . . . . . . . . 41

B DATA SHEET. . . . . . . . . . . . . . . . . 43

C INFORMED CONSENT. . . . . . . . . . . . . . . . . 45 


\section{LIST OF TABLES}

TABLE

PAGE

I Amplitude in Microvolts for Waves I, III, and

$\mathrm{V}$ for the Four Presentation Rates with

Rarefaction ( $R$ ) and Condensation (C)

Clicks . . . . . . . . . . . . . .

II Latency in Milliseconds for Waves I, III, and

$\mathrm{V}$ for the Four Presentation Rates with

Rarefaction ( $R$ ) and Condensation (C)

Clicks . . . . . . . . . . . . . . .

II Amplitude Ratios for Wave V/I for the Four

Presentation Rates for Rarefaction ( $R$ ) and

Condensation (C) Clicks . . . . . . . . 


\section{LIST OF FIGURES}

F IGURE

PAGE

1. ABR Waveforms for Four Presentation Rates for Rarefaction Clicks from one Normal-Hearing Subject . . . . . . . . . . . . . .

2. Amplitude in Microvolts of Wave I as a Function of Rate for Rarefaction and Condensation Clicks . . . . . . . . . . . . . . . . .

3. Amplitude in Microvolts of Wave III as a

Function of Rate for Rarefaction and

Condensation Clicks . . . . . . . . . .

4. Amplitude in Microvolts of Wave $V$ as a Function

of Rate for Rarefaction and Condensation

Clicks . . . . . . . . . . . . . .

5. Latency in Milliseconds for Wave I as a Function of Rate for Rarefaction and Condensation Clicks . . . . . . . . . . .

6. Latency in Milliseconds for Wave III as a

Function of Rate for Rarefaction and

Condensation Clicks . . . . . . . . . . . .

7. Latency in Miliseconds for Wave $V$ as a Function of Rate for Rarefaction and Condensation Clicks . . . . . . . . . . 
8. Amplitude Ratio for $V / I$ as a Function of Rate for Rarefaction and Condensation Clicks . . . . . . . . . . . . . . . 


\section{CHAPTER I}

\section{INTRODUCTION}

Research on the Auditory Brainstem Response (ABR) has been dominated by attempts to develop techniques to enhance the clarity of the ABR waveform and to define the parameters that separate normal from abnormal responses. Factors which affect the ABR waveform include the type of stimulus, the state of the auditory system, and recording variables such as the types of instrumentation used, electrode configuration, and signal extraction techniques. The stimulus parameters that affect the ABR waveform are intensity, spectral content, rise-fall time, and shape of the waveform envelope (Stockard, Stockard, Westmoreland, and Corfits, 1979; Stockard, stockard, and Sharbrough, 1978; Hall, 1984). Protocols for clinical use of the ABR have been developed as a result of much research on the effect of these variables.

Two other important stimulus variables that affect the $A B R$ are the rate and polarity of the stimulus. Stimulus rate refers to the number of presentations of a stimulus over a given unit of time. Polarity refers to the initial phase of the stimulus. For a click stimulus, it is the direction the earphone diaphragm initially moves given a voltage input. The polarity can be either rarefaction or condensation. Rarefaction is produced by initially pulling the earphone 
diaphragm away from the tympanic membrane and condensation is produced by initially pushing the earphone diaphragm towards the tympanic membrane.

There have been numerous studies on the effects of stimulus rate and polarity. Several authors have demonstrated that as the rate of a click is increased, the latencies of components or waves of the ABR are increased (Stockard et al., 1978; Bergholtz, 1981; Hall, 1984). While the effect of stimulus rate appears to be consistent across studies, the effects of polarity are less so. Various authors have studied the effects of polarity and reported inconsistent results. Borg and Lofqvist (1982) reported shorter latencies in $30 \%$ of their subjects with condensation clicks rather than rarefaction clicks. Emerson, Brooks, Parker, and Chiappa (1982) found latencies to be shorter with rarefaction clicks while Ruth, Hildebrand, and Cantrell (1982) found no noticeable influence. Part of this inconsistency is that various authors have used different methodologies and different equipment.

One of the possible reasons for the inconsistency of the effect of polarity across studies is that there may be an interaction between stimulus rate and polarity. That is, the effect of polarity might depend on the stimulus rate. Since different investigators used different presentation rates, this might account for their discrepant results. In order to determine if this is the case, the present study examined the effect of stimulus rate and polarity on latency, amplitude, 
and amplitude ratio of the waves I, III, and V, components of the ABR waveform.

Auditory brainstem responses were obtained with rare-

faction and condensation click stimuli delivered at rates of $11.1,21.1,41.1$, and 81.1 clicks per second. 
CHAPTER II

REVIEW OF THE LITERATURE

The ABR is a powerful clinical tool that is used to determine auditory status in infants, in the difficult-totest patient, and to detect retocochlear abnormality (Rowe, $1981)$

The Central Nervous system (CNS) generates spontaneous, random bioelectric activity in the absence of sensory stimulation (Jacobsen and Hyde, 1985). This electrical activity can be recorded using electrodes attached to the scalp and makes up the electroencephalogram (EEG) (Jacobsen and Hyde, 1985). When the CNS is stimulated using sound, electrical activity is generated and can be recorded using electrodes on the scalp. These auditory evoked potentials (AEP) can be computer "averaged" using the principal of algebraic summations of the electrical activity following repeated stimulation (Jacobsen and Hyde, 1985). This AEP is then extracted from the ongoing EEG activity, resulting in waveforms up to 500 ms following the offset of stimulation. AEP's can be categorized according to their latencies. Early latency response occurs in the first $10 \mathrm{~ms}$ following stimulation, middle latency response occurs $10-50 \mathrm{~ms}$ following stimulation, late response occurs $50-300 \mathrm{~ms}$ following stimulation, and slow response occurs $300-500 \mathrm{~ms}$ following stimulation. 
The ABR is a short latency response occurring in the first 10 ms following stimulation. In general, the larger the latency of the wave, the higher in the auditory pathway its point of origin. The principal parts of the auditory nervous system are the cochlea, the auditory nerve, the cochlear nucleus, superior olivary complex, lateral lemniscus, inferior colliculus, and the medial geniculate body.

Jewett and Williston (1971) first described the short latency auditory evoked potentials over the first $10 \mathrm{~ms}$ and labeled them waves I-VII. The origin of these waves is thought to correspond to points in the auditory system. Møller and Janetta (1985) give neural generators as follows: wave I originating from the auditory nerve, wave II originating from the cochlear nucleus, wave III from the dorsal cochlear nucleus, wave IV from the superior olivary complex, wave $V$ from the lateral lemniscus, wave VI from the inferior colliculus, and wave VII originating from the inferior colliculus also. These points of origin were obtained using animals and humans in experiments.

Research on the $A B R$ has been dominated by techniques to better enhance waveform and by attempts to define the parameters that separate normal from abnormal responses (Jacobsen, $1985)$

A number of variables regarding the $A B R$ have been studied. These include electrode placement, stimulus rate, stimulus intensity, filtering, stimulus polarity, stimulus envelope, and recording mode. A discussion of all of these 
variables is beyond the scope of this study; hence attention will focus upon the effects of stimulus rate and polarity. This thesis will include an explanation of the criteria for clinical use.

\section{CRITERIA FOR ABR INTERPRETATION}

An understanding of the ABR measures utilized clinically is critical to the understanding of the research data on the ABR. Therefore, a brief discussion of these measures is in order. There are five major response parameters: (1) absolute latency, (2) absolute amplitude, (3) amplitude ratio (AR), (4) interpeak latency (IPL), and (5) waveform morphology (Rowe, 1981; Bergholtz, 1981; Jacobsen, 1985). Wave latency is defined as the time delay from stimulus onset to any identified peak within the evoked response (Bergholtz, $1981)$

Absolute amplitude is typically measured from the positive peak of an $A B R$ wave to the negative valley (Glattke, 1983; Jacobsen, 1985). Bergholtz (1981) and Rowe (1981) state that there is wide variation within and between individuals in the amplitudes of their responses. Both Bergholtz and Rowe suggest the use of the relative amplitude of the different waves of the $A B R$ and have examined the amplitude ratio between the component peaks such as $V / I$ or $V / I I I$.

The IPL refers to the time difference between the two ABR wave components (Bergholtz, 1981). The IPL measure is one of the most commonly used clinical measures and is the 
most powerful criterion in assessing retrocochlear function (Rowe, 1981; Jacobsen, 1985). IPL's are most commonly determined for I-V, III-V, and I-III.

Waveform morphology can be defined as the structure or form of the ABR component peaks. This is a very subjective criterion and must be considered with other basic audiological data in order to have diagnostic significance. Morphology takes into consideration the overall shape of the ABR response, presence of various waveform components, and their amplitudes.

\section{THE EFFECTS OF STIMULUS RATE ON THE ABR}

\section{Latency}

The effects of varying stimulus rates upon the ABR have been studied extensively. As the rate is increased, latency of the ABR is increased (Stockard, Stockard, and Sharbrough, 1978; Bergholtz, 1981). Lasky (1984) and Hall (1984) observed that a linear function adequately expressed the relationship between stimulus repetition rate and wave $V$ latency, but was inappropriate for waves I and III. Gerling and FinitzoHieber (1983) found an increase in wave $V$ latency with increasing repetition rate and defined an abnormally large shift of wave $V$ latency as a shift greater than 3 standard deviations above the mean.

Fowler and Noffsinger's (1983) study on rate effects included three groups of subjects: normal-hearing controls, subjects with cochlear pathology, and subjects with VIII 
nerve/Brainstem pathology. They used stimulus rates of 10 and 50 tone pips per second and found significant latency increases for waves III and V. The wave I latency shift was the same for all three subject groups. Their results revealed latency changes for wave $V^{\circ}$ that were equivalent to those latencies produced with clicks in other studies. The latencies were longer in the neural group than in either of the other two groups. The $50 / \mathrm{sec}$. rate consistently produced longer latencies.

Paludetti, Maurizi, and Ottavini (1983) also found a linear relationship between latency and increased stimulus rate but it did not become significant until the rate exceeded $20 / \mathrm{sec}$. These investigators, using 26 male subjects with normal-hearing thresholds, also reported a small increase in amplitude for wave $V$ but found it to be inconsistent.

\section{Amplitude}

Lasky (1984), Bergholtz (1981), and Gerling and FinitzoHieber (1983) found a decrease in ABR wave amplitude as stimulus rate increased. Rowe (1978) observed no differences in amplitude for the rates of $10 / \mathrm{sec}$. and $30 / \mathrm{sec}$. Ruth, Hildebrand, and Cantrell (1982) noted a reduction in wave I amplitude of approximately $50 \%$ as rate increased over the range of 11.1 to 50.1 clicks/sec. Wave $\mathrm{V}$ amplitude reduction was approximately $30 \%$ over the range of rates studied. 
Interpeak Latency

The latency differences between some of the components of the $A B R$ are affected by an increased stimulus rate according to some authors while others have reported no effect. Stockard et al. (1978) observed that the mean I-V IPL increases by approximately $0.1 \mathrm{~ms}$ for each 20/sec. increase in rate. As noted, Rowe (1978) found an increase in wave I latency with stimulation rates 10 to 30 per second. He, therefore, concluded that the IPL's of waves I-III and I-V were affected due entirely to the increased latency of wave $I$. Paludetti et al. (1983) using stimulus rates of 10, 20, 50, and 100 per second found the IPL for waves III-V and III-II remained constant.

\section{Waveform Morphology}

Paludetti et al. (1983) found that waveform morphology did not show much variation when $10 / \mathrm{sec}$. or $20 / \mathrm{sec}$. were used. However, the waveforms become less distinct at $50 / \mathrm{sec}$. and $100 / \mathrm{sec}$. Rowe (1978) reported that rate had no effect on the $A B R$ waveform using the rates of $10 / \mathrm{sec}$. and $30 / \mathrm{sec}$. Gerling and Finitzo-Hieber (1983) found that high stimulation rates (above $30 / \mathrm{sec}$. ) result in less distinct waveforms. Hall (1984) also found that at very high stimulus rates $A B R$ waveforms deteriorated, referring to rates above $30 / \mathrm{sec}$. The mean I-V IPL increases by approximately $0.1 \mathrm{~ms}$ for each 20/sec. increase in rate. Hall (1984) gives a latency shift of 0.40 milliseconds for wave $V$ as rate is increased from 20 to 80 clicks per second. 
The effects of varying stimulation rate seem clear for the most part. Increasing rates causes an increase in latency, particularly in wave $I$, an increase in the IPL'S, a reduction in amplitudes, and a change in the waveform morphology. In general, these effects are significant at rates of about 30/sec. (Hall, 1984; Stockard et al., 1978).

THE EFFECTS OF STIMULUS POLARITY ON THE ABR

Physiological evidence indicates that the afferent auditory nerves are excited only during one half of a sinusoidal stimulus, namely when the stapes moves out of the oval window. The basilar membrane moves toward the scale vestibuli and the stereocilia of the receptor cells in the organ of corti are bent in the organ of Corti. This phase sensitivity is seen clearly in the activity pattern of single units in the auditory nerve. Upon phase reversal, the peak of the impulse activity is shifted in time by half a cycle (Borg and Lofquist, 1982, p. 227).

While the effect of stimulus rate appears to be consistent across studies, the effects of polarity are less so. Some researchers have found polarity effects and others have not. Bergholtz (1981) found the relationship between $A B R$ latency and polarity to be "complex." Stockard et al. (1978) noted the "variability" of the ABR because of polarity.

The question of polarity concerns the direction in which the earphone diaphragm moves given a rectangular voltage input (Jacobsen, 1985). This is an important matter since there are no standards for earphone wiring and, therefore, each clinic must determine the phase of its earphones and mark them accordingly (Jacobsen, 1985). Hall (1984) recommends documenting stimulus polarity in normative and 
clinical ABR measurements. Stockard et al. (1978) stated that phase is important in the presence of high frequency hearing loss.

\section{Latency}

Stockard et al. (1978) noted that in most cases, wave V stays at the same latency while other latencies (especially wave IV) tend to be shorter for rarefaction clicks than for condensation clicks. Lynn, Robinson, and Schwan (1985) found wave I latency was significantly shorter with rarefaction clicks in 21 of 31 ears, longer in 5 ears, and equal in 5 ears. Latencies for waves III and V did not show a consistent trend favoring either rarefaction or condensation, or alternating polarities. Robinson, Lynn, and Schwan (1985) noted that wave I latency was significantly shorter with rarefaction versus condensation clicks in 9 out of 31 ears. Waves III and $V$ were significantly longer with rarefaction than condensation clicks in 8 ears and 6 of 12 ears respectively. Latencies for waves I, III, and V were equal in 2 , 1 , and 8 ears, respectively.

Tvete and Haugsten (1981) studied the ABR in cats, examining latency as a function of polarity, intensity, and acoustic waveform. They found that the effect of changing the stimulus polarity on the latency is dependent upon the acoustic waveform and intensity of the stimulus. At high stimulus levels, the observed polarity effect was always most pronounced. The shortest latencies were always observed for rarefaction signa1s. At lower stimulus intensities, the 
latency shift due to polarity became smaller. No systematic variation in latency could be demonstrated for rarefaction stimuli at any stimulus level. For condensation stimuli, large latency differences were found at high intensity levels. This finding suggests that the first negative peak in the acoustical signal is responsible for the ABR at high stimulus level.

Ornitz, Mo, Olson, and Walter (1980) compared normal and autistic subjects using rarefaction and condensation clicks with peak acoustic energies at 3150 and $5000 \mathrm{~Hz}$. No significant differences were found in the latencies of the peaks between the two groups. Latencies of vertex positive peaks I-V were similar to values reported from other laboratories, allowing for the influence of differences in sound intensity and high pass filtering. For the combined group of subjects, rarefaction clicks produced a significantly earlier wave IV response than condensation clicks. Waves I and II latencies were significantly earlier in response to rarefaction than to condensation clicks but only with the $5000 \mathrm{~Hz}$ click. The condensation-rarefaction difference itself was significantly greater in response to the $5000 \mathrm{~Hz}$ click than for the $3150 \mathrm{~Hz}$ click for wave II. For normalhearing subjects, wave IV occurred about $0.2-0.3 \mathrm{~ms}$ earlier in response to rarefaction than to condensation clicks. Waves I and II occurred about $0.1 \mathrm{~ms}$ earlier in response to rarefaction clicks when $5000 \mathrm{~Hz}$ clicks were used. Ornitz, Mo, Olson, and walter concluded that: 
- - latency differences are confined primarily to wave IV and to a lesser extent, waves $I$ and II, and do not involve wave $V$. Rarefaction responses lead condensation responses by about $0.2-0.3 \mathrm{~ms}$, a range compatible with the assumption that the response is evoked only by the rarefaction phase of the stimulus $(1980$, p. 252).

These findings are compatible with the view that "two separate subsystems, activated in parallel, produce waves that are respectively dependent and independent of the direction of the sound pressure" (Ornitz et a1., 1980, p. 253).

Kevanishvili and Aphonchenko (1981) reported that latency was little affected by the polarity change. The differences were shorter peak latency of waves I and IV with rarefaction clicks, and shorter peak latency of wave $V$ with condensation clicks. These researchers concluded that excitation of the VIII nerve should occur with only a rarefaction phase of a click. With condensation clicks, the peak latencies should be delayed by the duration of the initial click phase. Kevanishvili and Aphonchenko concluded that :

- . neither rarefaction nor condensation clicks seem to have any advantage in audiologic $A B R$ investigations where an identification of wave $\mathrm{V}$ is of primary importance and stimuli of low sensation level (SL) are used. Rarefaction clicks are likely to have preference in otoneurologic investigations where the registration of $A B R$, with all individual components is required and therefore, high intensity stimuli are necessary (p. 146).

Maurer, Schafer, and Leitner (1980) reported measurable changes with reversal of polarity using tone pips. Rarefaction pips elicited an earlier wave I. 
Similarly, Ruth et al. (1982) found rarefaction clicks tended to produce the shortest latency for wave I. However, they did not find a statistically significant difference at either intensity ( $50 \mathrm{~dB} \mathrm{HL}$ and $70 \mathrm{~dB} H L)$ for rarefaction, condensation, and alternating polarity. No noticeable influence on wave III or $V$ was reported.

Borg and Lofquist (1982) found for wave $V$ that $30 \%$ of their 7 normal-hearing subjects had shorter latency for condensation than rarefaction. In the subjects with conductive hearing loss, the absolute value of condensation-rarefaction latency difference is seen to approximate that for normals. In 13 of 27 test runs, rarefaction latency was shorter than condensation latency for wave V. In subjects with cochlear hearing 1oss, there was a rapid increase in condensationrarefaction difference as the wave $V$ latency increased. For half the cochlear subjects, the condensation-rarefaction differences were clearly above the range for the normals. In 19 ears the rarefaction latency was shorter than condensation latency. In subjects with acoustic neurinomas, the wave $V$ latencies ranged up to $10 \mathrm{~ms}$, a latency not seen in the cochlear or normal group. Borg and Lofqvist conclude the condensation-rarefaction difference was not related to wave $V$ latency. They conclude the condensation-rarefaction difference shows different features in conductive, cochlear, and retrocochlear hearing loss.

Emerson, Brooks, Parker, and Chiappa (1982) found minor alterations in the latency and amplitude of waves I-V, with 
rarefaction clicks versus condensation clicks. Wave I latency was significantly shortened, while the latencies of waves III and $V$ were not significantly shorter.

\section{Amplitude and Waveform}

Kevanishvili and Aphonchenko (1981) noted that with rarefaction clicks, wave II and IV were well defined while with condensation clicks they had smaller amplitudes or were absent. With a change in click polarity, wave I was also substantially changed. Wave III had smaller amplitudes and a flatter pattern for condensation polarity. The difference appeared to be a consequence of alteration of preceding and following components of wave II and IV. The waveform and amplitude of the later ABR components ( $V$ and $V I$ ) did not show any apparent change with the polarity inversion.

Emerson et al. (1982) contended that rarefaction clicks produce the clearest waveforms and should be used clinically. Condensation clicks can be used in those patients in whom rarefaction clicks do not produce clear waveforms or wave $\mathrm{V}$ appears absent. Condensation clicks tended to fuse waves IV and $V$ into a single broad peak, whereas rarefaction clicks produced two distinct waves. Wave I amplitude was lower with condensation clicks in $75 \%$ of the ears tested, higher in $18 \%$, and unchanged in $7 \%$. Wave $\mathrm{V}$ amplitude was higher with condensation clicks in $66 \%$, lower in $30 \%$, and unchanged in $4 \%$ of subjects. No significant effect upon wave III was observed. 
Maurer, Schafer, and Leitner (1980) observed that alternating polarity decreased the stimulus artifact so that the first upgoing vertex positive deflection was clearly seen. Rarefaction stimuli seem to have a better synchronizing effect, since the amplitude of waves I-IV were Iarger and waves IV and $V$ were clearly separated. Condensation stimuli had less effect on their subjects in producing clearly discernible waves. They reported smaller amplitudes for waves I-III while waves IV and $V$ were fused into a single complex. Rarefaction pips elicited a nearly normal wave II while condensation pips produced a notched wave II with a small amplitude. They concluded that amplitude changes measurably with reversal of polarity. Amplitudes were significantly larger in response to rarefaction pips for waves $I$ and IV and clearly separated waves IV and V. The tendency for condensation pips to merge to a single IV/V complex or a single wave $\mathrm{V}$ was observed with a larger amplitude compared to those elicited by rarefaction pips. Ruth, Hildebrand, and Cantrell (1982) found that at $50 \mathrm{~dB}$ nHL there was no change in amplitude as a function of polarity; however, at $70 \mathrm{~dB}$ nHL, they noted a significant difference with polarity reversal in wave I amplitude. Rarefaction resulted in the larger amplitude for wave $I$. They reported significant changes in waves III and V amplitude as a function of polarity. 


\section{Interpeak Latency}

Interpeak latencies may differ as much as $0.3 \mathrm{~ms}$ and relative amplitude values by $50 \%$ in the same individual (Stockard et al., 1978).

Emerson et al. (1982) found the I-III and I-V IPL were slightly greater for rarefaction clicks than for condensation clicks. Lynn, Robinson, and Schwan (1985) also reported the I-III, III-V, and I-V IPL's to be longer for rarefaction than condensation clicks in most ears. The IPL's were significantly longer with rarefaction compared to condensation in 10 of 17 ears for the I-III IPL and 2 of 7 ears for III-V IPL. IPL's were equal in only 1 of 11 ears for the I/V. 
CHAPTER III

METHODS

SUBJECTS

Fourteen male subjects, ages 17 to 30 years, were included in the study. Each subject had no history of hearing loss, chronic otologic problems, head trauma or anomalies of the central nervous system, or other neurological involvement. Each demonstrated pure tone thresholds of $15 \mathrm{~dB}$ HL or lower for test frequencies at the octave intervals from 500 through $8000 \mathrm{~Hz}$. All had normal tympanograms just prior to testing. Ipsilateral and contralateral acoustic reflexes were elicited in each subject using a $1000 \mathrm{~Hz}$ stimulus at presentation levels ranging from 70 to $95 \mathrm{~dB}$ HL. Each subject was required to pass ABR criteria testing prior to inclusion in the study. The criteria consisted of a well defined and repeatable wave I, III, and V elicited at $70 \mathrm{~dB}$ nHL and a repeatable wave $V$ response at $30 \mathrm{~dB}$ nHL with a broad band negative polarity click stimuli with a rate of $21.1 \mathrm{clicks} / \mathrm{second}$.

Click stimuli for the present study consisted of rectangular pulses with duration of 100 microseconds generated by a Nicolet 1001 Clinical Averager. These were delivered by means of Telex $1470 \mathrm{~A}$ earphones fitted with Telephonic 
MX 41/AR cushions. Polarity of the click stimuli was determined by means of a Grass Instruments Earphone Polarity Tester (Model EPT-A). Click presentation rate was monitored with an oscilloscope.

Behavioral thresholds were determined for the click stimuli for 10 normal-hearing subjects prior to the study. The mean threshold was designated as $0 \mathrm{~dB}$ nHL and is used as the clinic norm.

Auditory evoked responses were recorded with electrode placements at the upper forehead (noninverted), from the ipsilateral mastoid (inverted) and the contralateral mastoid (ground). Grass silver cup electrodes (E55-H) were connected to a Nicolet CA 1000 Clinical Averager. The CA 1000 was set to the artifact rejection mode with an analysis time of $10 \mathrm{~ms}$ and a sensitivity of either $\pm_{5}$ or \pm 10 microvolts, depending upon the activity level of the individual subject. All subjects were tested in a single-walled sound treated room while reclining. Interelectrode impedance was at or below 1000 ohms, as measured on the Nicolet Model 200A.

\section{PROCEDURES}

Rarefaction and condensation clicks were presented to the right ear of each subject at rates of $11.1,21.1,41.1$, and 81.1 clicks per second. The order of presentation rate was randomized across subjects.

The click stimuli were presented at a level of $70 \mathrm{~dB}$ nHL without masking the nontest ear. A total of 2000 sweeps 
were made for each averaged response. A minimum of two runs was conducted at each presentation rate for each stimulus polarity. All evoked electrophysiological responses were stored on floppy disk for later analysis. Immediately following data collection for each subject, the absolute latency and amplitude values for waves I, III, and V were established for each condition. Absolute latency values were measured from the onset of the click to the positive peaks of each of the three waves under investigation. Amplitude values were measured from the peak positive deflection to the subsequent lowest point of the negative deflection. 
CHAPTER IV

RESULTS

Figure 1 (p. 22) shows the ABR waveforms of one norma1hearing subject. The latency changes as stimulus rate was increased can be seen.

\section{TEST-RETEST RELIABILITY}

Test-retest reliability was examined since it is important to determine the degree of confidence one can have in obtained test scores across trials. Consequently, an examination was made of the intrasubject variability of the amplitudes of waves I, III, and V. This task was accomplished by subtracting the amplitude of the second run (Run 2) from the amplitude of the first run (Run 1) and computing a mean difference score and a standard error of the mean difference. These values allow for a confidence interval to be constructed wherein there is a $95 \%$ probability that the amplitude will be within two standard errors of the mean difference. The standard error of the mean difference values were $.006 \mathrm{uv}$, $.006 \mathrm{uV}$, and $.008 \mathrm{uV}$ for waves I, III, and V, respectively. Since these calculated values were so small, the individual data from both runs for each condition were pooled by summing and then divided by two. That is, the mean of the two runs served as raw data in the measurement of amplitude. 


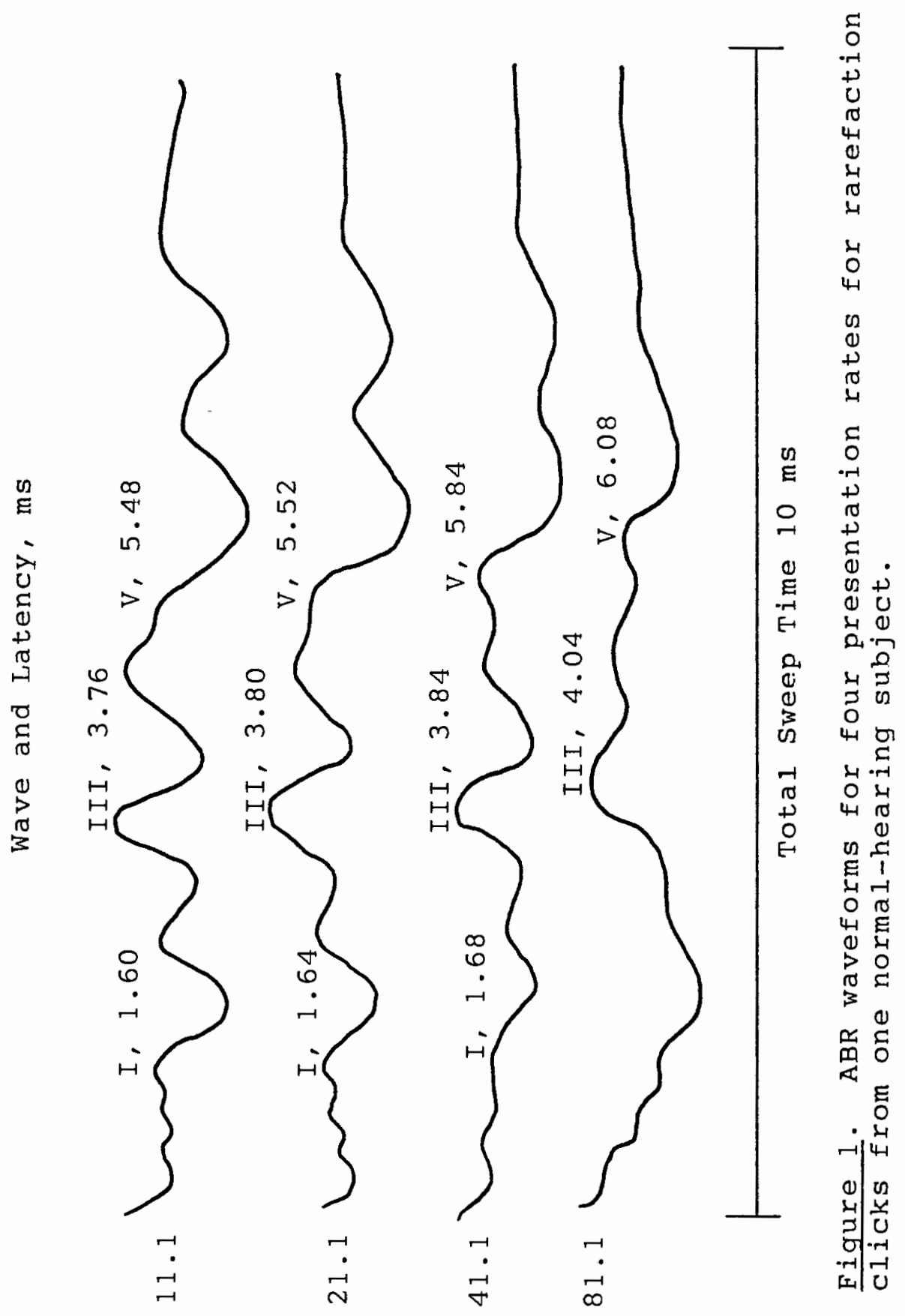

syaț fo uoţequasaxd fo ә7еd 
The reliability of response latency within subjects was also examined, using the same method as for amplitude. The standard error of the mean difference was .010, .005, and $.005 \mathrm{~ms}$ for waves $I$, III, and $V$, respectively. Since the standard error values were sosmall, the two runs were combined as they were for amplitude. Again, the pooled data served as raw data in the measurement of the wave latencies.

\section{AMPLITUDE}

Fjgures 2,3 , and 4 show amplitude plotted as a function of stimulus rate for waves I, III, and V, respectively. One will readily note in Figures 2 and 3 that as rate increased, the mean amplitudes of waves I and III decreased. On the other hand, Figure 4 shows that wave $V$ amplitude appears to be quite resistant to the effects of stimulus rate over the range incorporated in the present study. That is, wave V amplitude does not decrease with rate as it does for waves I and III. It will be noted also in Figures 2 and 3 that rarefaction clicks produced larger mean amplitudes for waves I and II for all rate conditions. However, condensation clicks produced larger amplitudes for wave $V$ as shown in Figure 4. For the rate of 81.1 clicks per second, wave I amplitude was markedly decreased and essentially eliminated from measurement. The mean values in microvolts and corresponding standard deviations of amplitude are given in Table I, p. 27. 


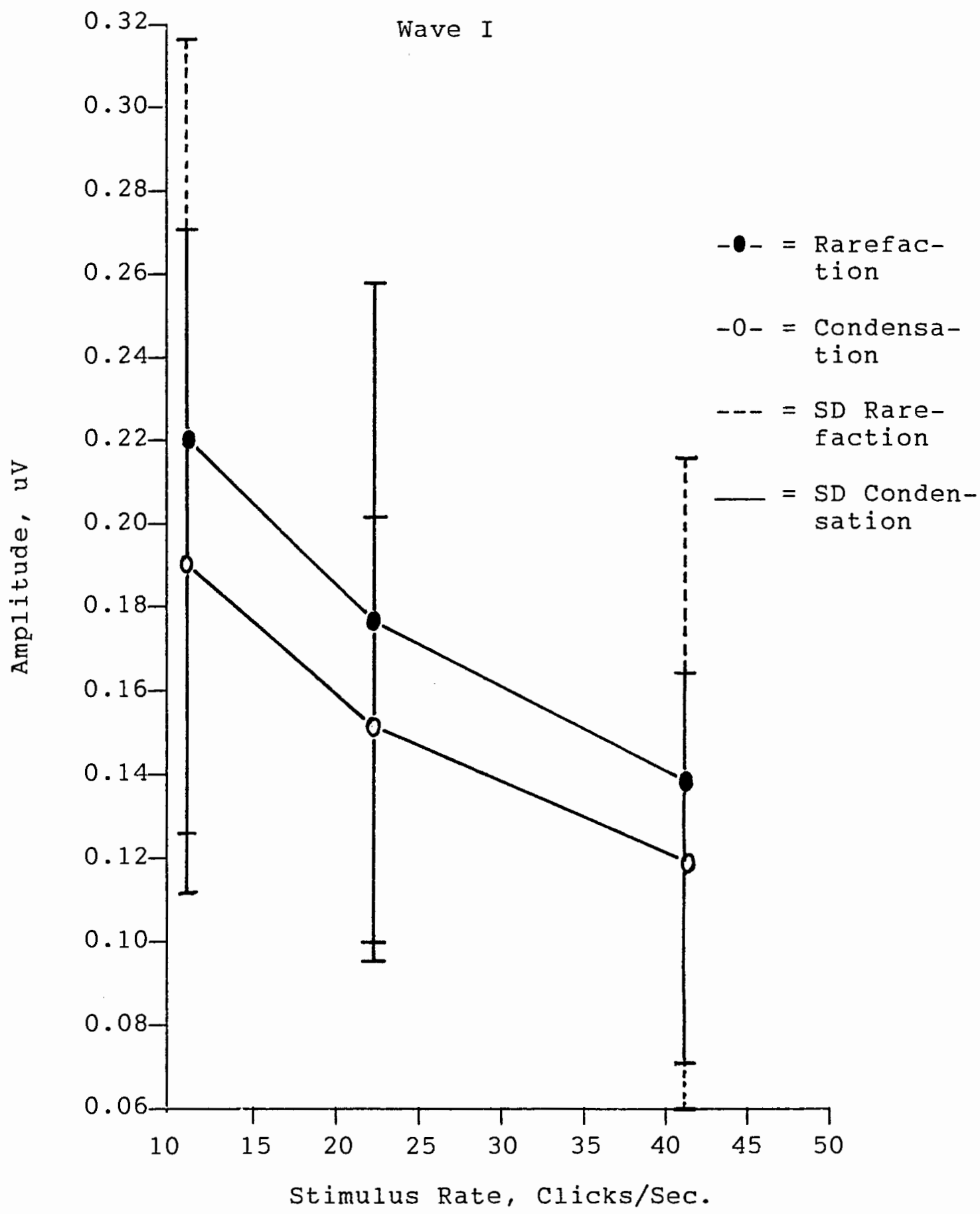

Figure 2. Amplitude in microvolts of wave $I$ as a function of rate for rarefaction and condensation clicks. 


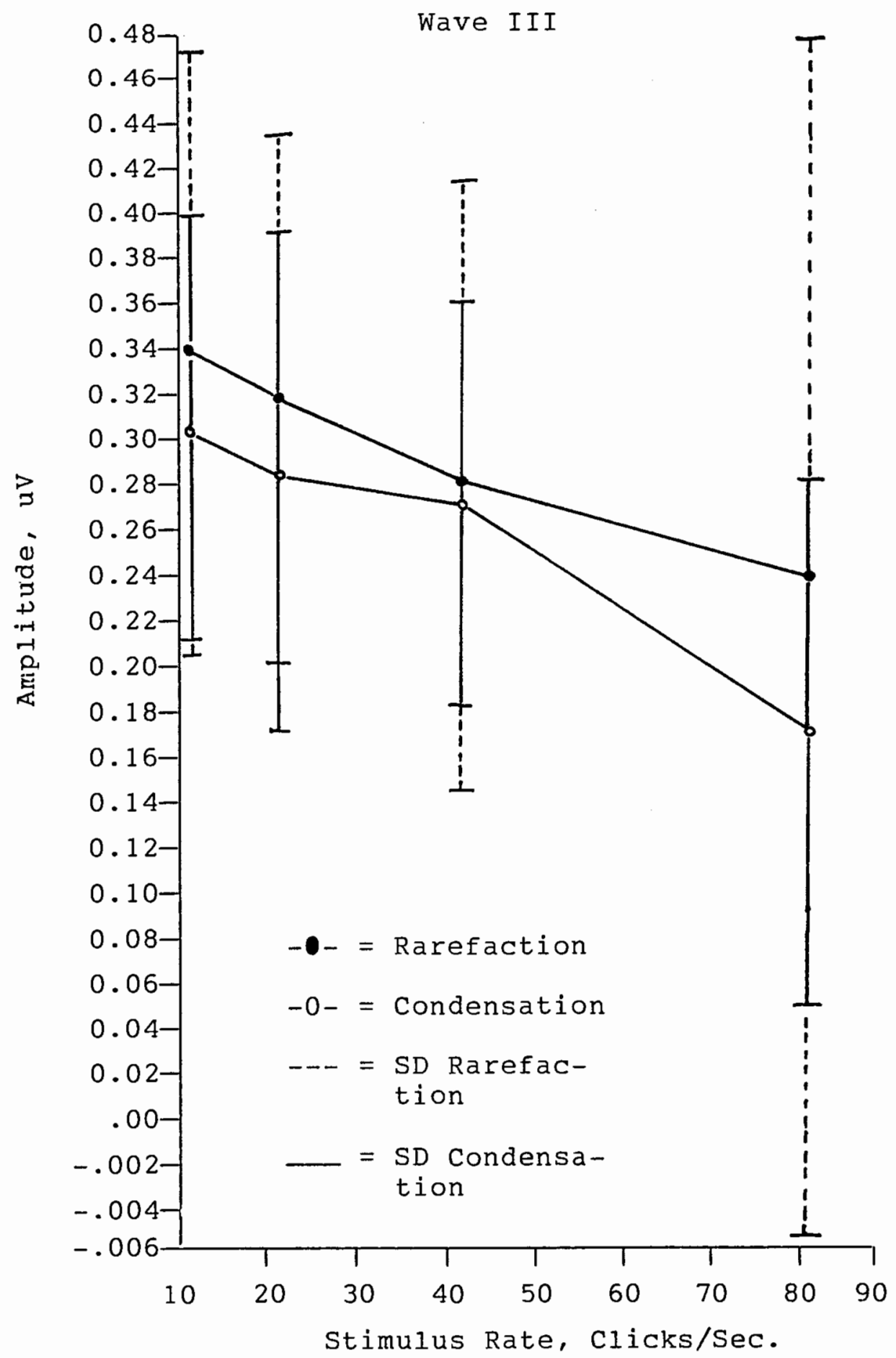

Figure 3. Amplitude in microvolts of wave III as a function of rate for rarefaction and condensation clicks. 


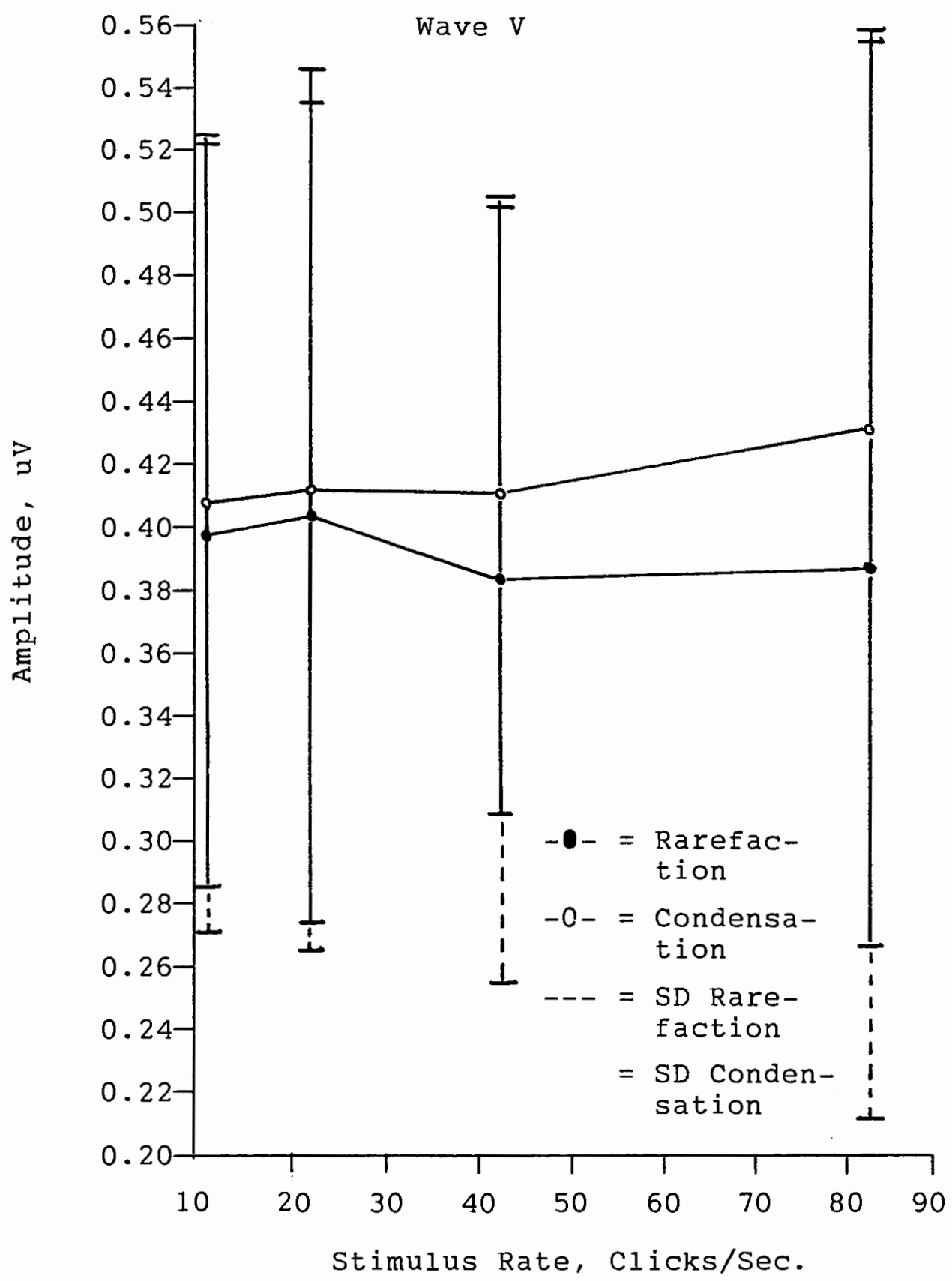

FIGURE 4. Amplitude in microvolts of wave $V$ as a function of rate for rarefaction and condensation clicks. 
TABLE I

AMPLITUDE IN MICROVOLTS FOR WAVES I, III, AND V FOR THE FOUR PRESENTATION RATES WITH RAREFACTION (R) AND CONDENSATION (C) CLICKS

\begin{tabular}{|c|c|c|c|c|c|c|}
\hline \multirow{2}{*}{$\begin{array}{c}\text { Rate } \\
\text { Clicks/Sec. }\end{array}$} & \multicolumn{2}{|c|}{ Wave I } & \multicolumn{2}{|c|}{ Wave III } & \multicolumn{2}{|c|}{ Wave $\mathrm{V}$} \\
\hline & $\mathrm{R}$ & $\mathrm{C}$ & $\mathrm{R}$ & $\mathrm{C}$ & $\mathrm{R}$ & $\mathrm{C}$ \\
\hline $\begin{array}{r}11.1 \\
\mathrm{SD}^{*}\end{array}$ & $\begin{array}{r}.220 \\
0.094\end{array}$ & $\begin{array}{r}.190 \\
0.079\end{array}$ & $\begin{array}{r}.338 \\
0.132\end{array}$ & $\begin{array}{r}.303 \\
0.095\end{array}$ & $\begin{array}{r}.398 \\
0.125\end{array}$ & $\begin{array}{r}.406 \\
0.120\end{array}$ \\
\hline $\begin{array}{r}21.1 \\
S D\end{array}$ & $\begin{array}{r}.176 \\
0.081\end{array}$ & $\begin{array}{r}.150 \\
0.051\end{array}$ & $\begin{array}{r}.317 \\
0.116\end{array}$ & $\begin{array}{r}.280 \\
0.109\end{array}$ & $\begin{array}{r}.403 \\
0.133\end{array}$ & $\begin{array}{r}.409 \\
0.134\end{array}$ \\
\hline $\begin{array}{r}41.1 \\
\text { SD }\end{array}$ & $\begin{array}{r}.138 \\
0.078\end{array}$ & $\begin{array}{r}.118 \\
0.046\end{array}$ & $\begin{array}{r}.279 \\
0.135\end{array}$ & $\begin{array}{r}.271 \\
0.089\end{array}$ & $\begin{array}{r}.380 \\
0.121\end{array}$ & $\begin{array}{r}.406 \\
0.197\end{array}$ \\
\hline $\begin{array}{r}81.1 \\
\text { SD }\end{array}$ & - & - & $\begin{array}{r}.236 \\
-.241\end{array}$ & $\begin{array}{r}.168 \\
0.116\end{array}$ & $\begin{array}{r}.386 \\
0.171\end{array}$ & $\begin{array}{r}.433 \\
0.166\end{array}$ \\
\hline
\end{tabular}

* Standard deviation.

A two-way analysis of variance (ANOVA) was conducted for each of the three waves under study with rate as the between subjects factor (four levels: $11.1,21.1,41.1$, and $81.1 \mathrm{clicks} / \mathrm{sec}$.$) and polarity as the within subjects factor$ (two levels: rarefaction and condensation). The amplitude of the given wave was the dependent variable in each ANOVA. Analysis of the data for the three waves revealed a significant stimulus rate main effect upon amplitude for wave I $[F(2,26)=18.36, p<.01]$ and wave III $[F(3.39)=8.57$, $\mathrm{p}<.01]$. However, rate was not a significant main effect for wave $V$ amplitude at the .01 level $[F(3,39)=.22, p<.05]$. In contrast to the findings for stimulus rate, the polarity 
main effect was not significant for any of the three waves under study $[F(1,13)=1.02$ to $8.12, \mathrm{p}<.05]$. Furthermore, there were no significant interaction effects observed between rate and polarity for wave $I[F(2,26)=.15, p<.05]$ or wave III and $\mathrm{V}[\mathrm{F}(3,39)=.36$ to $.45, \mathrm{p}<.05]$.

\section{LATENCY}

Figures 5, 6, and 7 show latency plotted as a function of stimulus rate for waves $I, I I I$, and $V$, respectively. It is evident that as rate increased, so did the latency for all the waves under investigation. As can be seen in Figure 5, rarefaction stimuli produced a shorter latency for wave I but this trend cannot be noted for waves III and V. The mean latencies and standard deviations are shown in Table II, p. 32 .

As for amplitude, a two-way ANOVA was conducted for latency effects on each of the three waves under study. The analysis revealed that rate significantly affected response latency for a11 three waves: wave $I[F(2,26)=15.51$, $\mathrm{p}\langle .01]$; waves III and $\mathrm{V}[\mathrm{F}(3,39)=73.97$ to $75.15, \mathrm{p}<.01]$. Again, stimulus polarity demonstrated no significant effect upon the latency for al1 three waves $[F(1,13)=.041$ to .542 , $\mathrm{p}<.05]$. There was no observed interaction between rate and polarity for wave $\mathrm{I}[\mathrm{F}(2,26)=.064, \mathrm{p}<.05]$ or for waves III and $\mathrm{V}[\mathrm{F}(3,39)=.041$ to $1.98, \mathrm{p}<.05]$. 


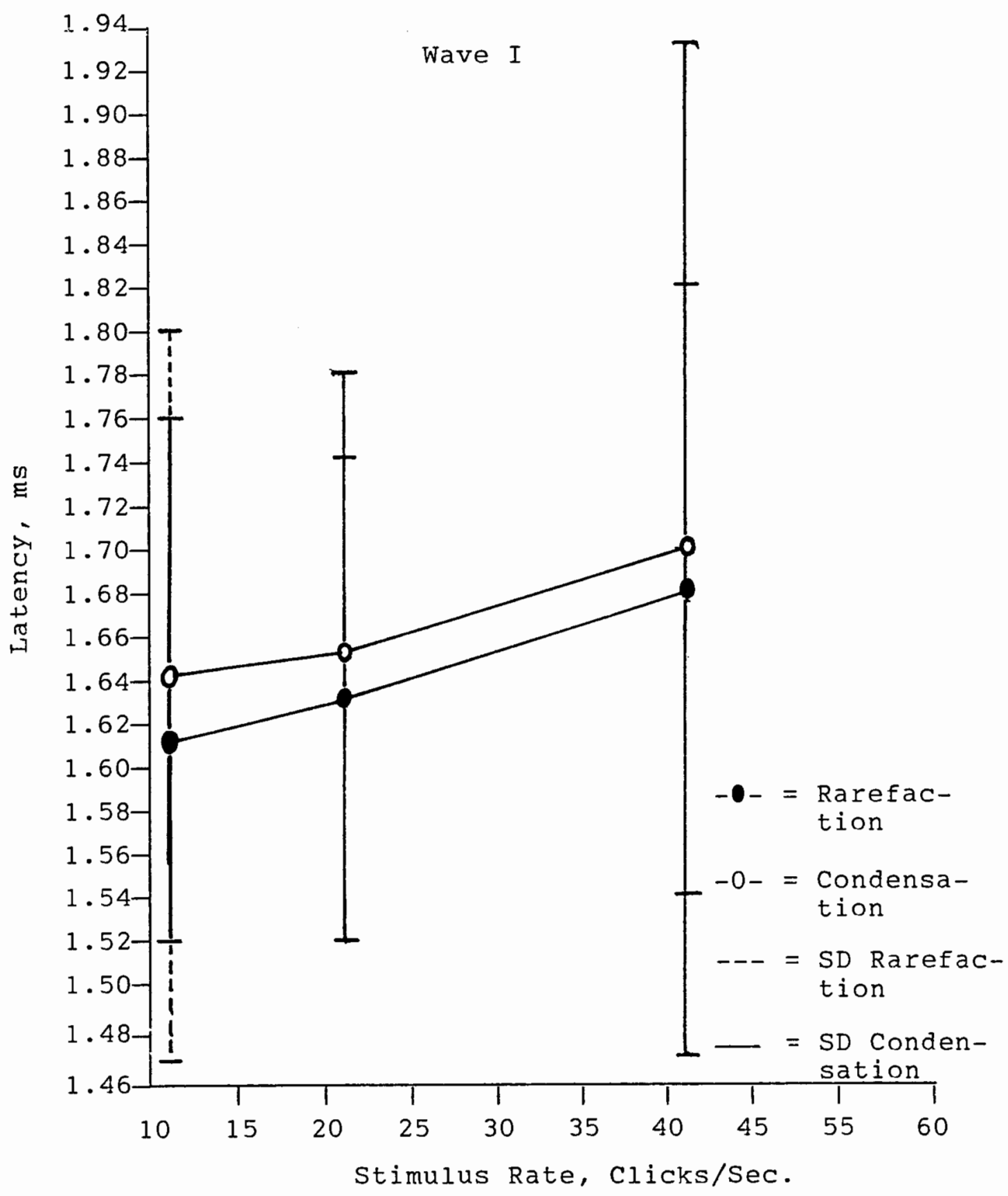

Figure 5. Latency in milliseconds for wave $I$ as a function of rate for rarefaction and condensation clicks. 


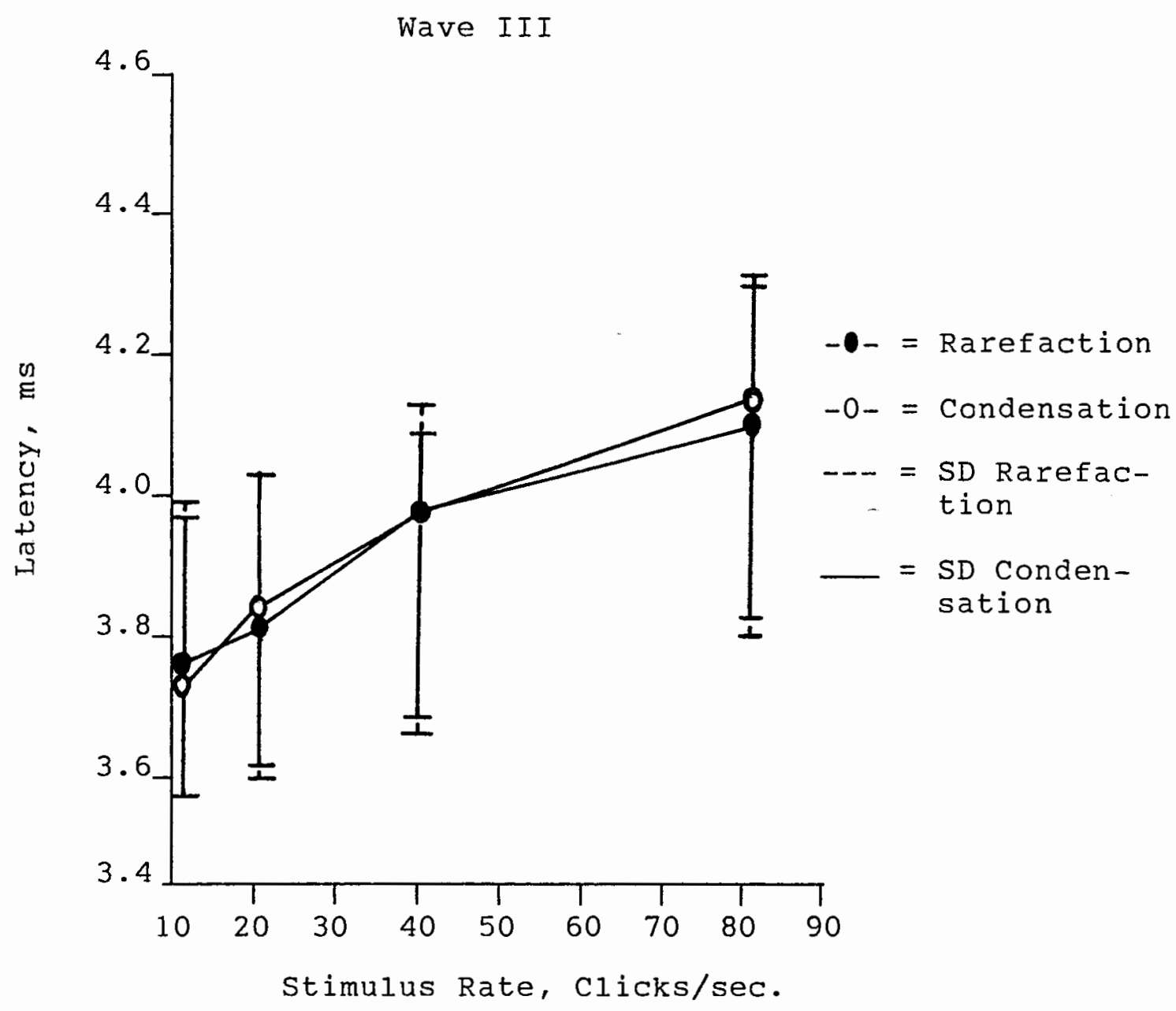

Figure 6. Latency in milliseconds for wave III as a function of rate for rarefaction and condensation clicks. 


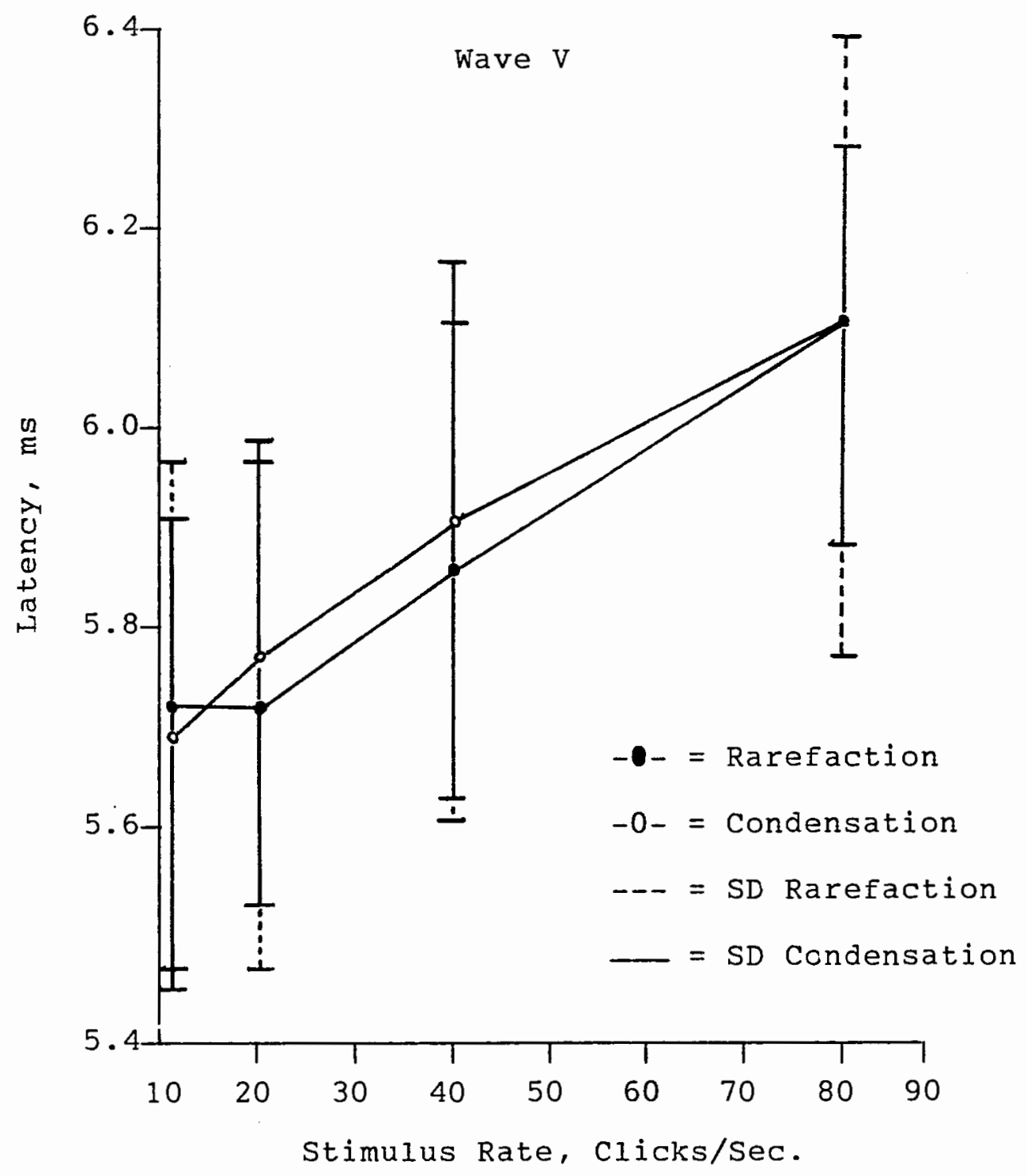

Figure 7. Latency in milliseconds for wave $\mathrm{V}$ as a function of rate for rarefaction and condensation clicks. 
TABLE II

LATENCY IN MILLISECONDS FOR WAVES I, III, AND V FOR THE FOUR PRESENTATION RATES WITH RAREEACTION (R) AND CONDENSATION (C) CLICKS

\begin{tabular}{|c|c|c|c|c|c|c|}
\hline \multirow{2}{*}{$\begin{array}{c}\text { Rate } \\
\text { Clicks/Sec. }\end{array}$} & \multicolumn{2}{|c|}{ Wave I } & \multicolumn{2}{|c|}{ Wave III } & \multicolumn{2}{|c|}{ Wave V } \\
\hline & $\mathrm{R}$ & $\mathrm{C}$ & $\mathrm{R}$ & C & $\mathrm{R}$ & $\mathrm{C}$ \\
\hline $\begin{array}{l}11 \cdot 1 \\
S D *\end{array}$ & $\begin{array}{l}1.61 \\
0.139\end{array}$ & $\begin{array}{l}1.64 \\
0.120\end{array}$ & $\begin{array}{l}3.77 \\
0.222\end{array}$ & $\begin{array}{l}3.76 \\
0.208\end{array}$ & $\begin{array}{l}5.71 \\
0.250\end{array}$ & $\begin{array}{l}5.67 \\
0.234\end{array}$ \\
\hline $\begin{array}{r}21.1 \\
\text { SD }\end{array}$ & $\begin{array}{l}1.63 \\
0.113\end{array}$ & $\begin{array}{l}1.65 \\
0.130\end{array}$ & $\begin{array}{l}3.81 \\
0.215\end{array}$ & $\begin{array}{l}3.82 \\
0.212\end{array}$ & $\begin{array}{l}5.71 \\
0.249\end{array}$ & $\begin{array}{l}5.75 \\
0.226\end{array}$ \\
\hline $\begin{array}{r}41.1 \\
\text { SD }\end{array}$ & $\begin{array}{l}1.68 \\
0.140\end{array}$ & $\begin{array}{l}1.70 \\
0.229\end{array}$ & $\begin{array}{l}3.89 \\
0.217\end{array}$ & $\begin{array}{l}3.89 \\
0.196\end{array}$ & $\begin{array}{l}5.85 \\
0.244\end{array}$ & $\begin{array}{l}5.90 \\
0.256\end{array}$ \\
\hline $\begin{array}{r}81.1 \\
\text { SD }\end{array}$ & $\begin{array}{l}- \\
-\end{array}$ & $\begin{array}{l}- \\
-\end{array}$ & $\begin{array}{l}4.08 \\
0.285\end{array}$ & $\begin{array}{l}4.10 \\
0.278\end{array}$ & $\begin{array}{l}6.08 \\
0.310\end{array}$ & $\begin{array}{l}6.08 \\
0.204\end{array}$ \\
\hline
\end{tabular}

* Standard deviation.

AMPLITUDE RATIO V/I

As can be seen in Figure 8 , the amplitude ratio for $V / I$ increased as the rate increased, almost doubling the magnitude between 11.1 and $41.1 \mathrm{clicks} / \mathrm{sec}$. While not reaching statistical significance, it can be observed that rarefaction clicks resulted in slightly smaller amplitude ratios than did condensation clicks. Table III, p. 34, shows the mean V/I amplitude ratios and corresponding standard deviations as a function of stimulus rate.

The two-way analysis of variance for the amplitude ratio for wave $V / I$ revealed a significant effect for stimulus rate $[F(2,26)=12.00, \mathrm{p}(.01)$. Polarity demonstrated no significant effect $[F(1,13)=.66, p<.05]$. There was no interaction $[F(2,26)=.26, \mathrm{p}<.05]$. 


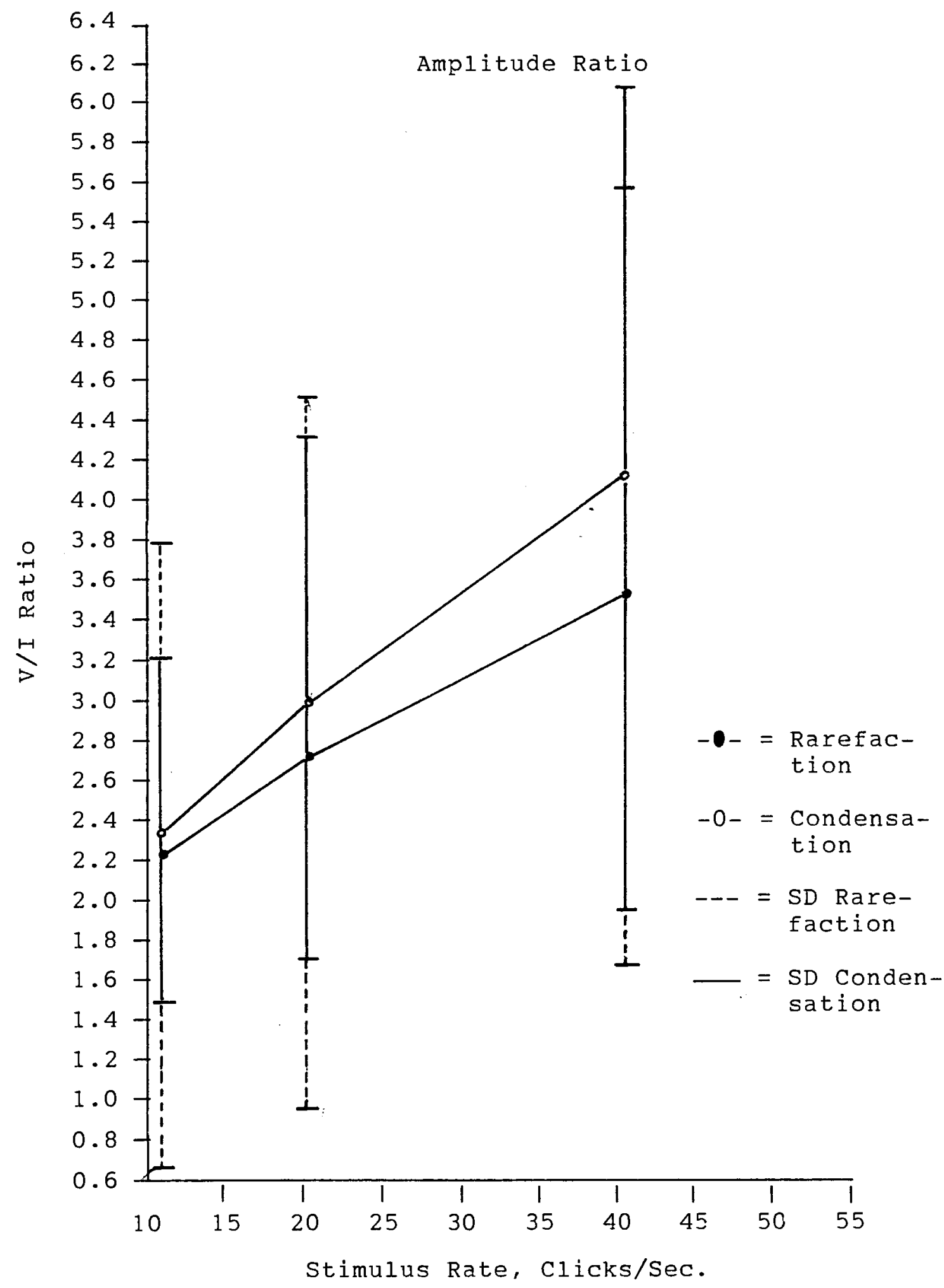

Figure 8. Amplitude ratio for $V / I$ as a function of rate for rarefaction and condensation clicks. 
TABLE III

AMPLITUDE RATIOS FOR WAVE V/I FOR THE FOUR PRESENTATION

RATES FOR RAREFACTION ( $R$ ) AND CONDENSATION (C) CLICKS

\begin{tabular}{c|cc}
\hline \multirow{2}{*}{$\begin{array}{c}\text { Rate } \\
\text { Clicks/Sec. }\end{array}$} & \multicolumn{3}{|c}{ Wave V/I } \\
\cline { 2 - 3 } & $\mathrm{R}$ & $\mathrm{C}$ \\
\hline 1.1 & 2.22 & 2.34 \\
$\mathrm{SD}^{*}$ & 1.57 & 0.87 \\
21.1 & & 2.98 \\
$\mathrm{SD}$ & 2.76 & 1.31 \\
& 1.80 & 4.12 \\
41.1 & & 2.19 \\
$\mathrm{SD}$ & 1.94 & - \\
81.1 & - & - \\
$\mathrm{SD}$ & - & \\
\hline
\end{tabular}

* Standard deviation. 


\section{CHAPTER V}

\section{DISCUSSION}

The results in the present study agree with the results reported by Lasky (1984), Bergholtz (1981), and Gerling and Finitzo-Hieber (1983) in regard to the amplitude data. The present results indicate that as rate is increased, the amplitude of the ABR waves decreased. This decrease was most noticeable for waves I and III. At the rate of 81.1 clicks per second, wave I was essentially eliminated. There was little effect upon the amplitude of wave $v$, which agrees with Fowler and Noffsinger (1983) who reported wave $V$ being most resilient to rate increases. In contrast to the rate findings however, polarity had no statistically significant effect on the amplitude of the ABR waves studied. However, this finding notwithstanding, some trends can be noted when viewing the raw data. Rarefaction clicks appear to yield a greater amplitude for waves I and III than do condensation clicks. These observations agree with a number of researchers (Ruth, Hildebrand, and Cantrel1, 1982; Maurer, Schafer, and Leitner, 1980; Emerson, Brooks, Parker, and Chiappa, 1982). For wave V, condensation clicks yielded a greater amplitude, agreeing with the data reported by Emerson et al. (1982). 
The latency data also reveals a significant effect as rate is increased. Again, this finding is compatible with the results of stockard, Stockard, and Sharbrough (1978), Bergholtz (1981), and Hall (1984). On the other hand, there was no polarity effect, although a trend can be noted. For wave I, rarefaction clicks tended to yield a shorter latency, a finding which agrees with results reported by Emerson et al. (1982), Kevanishvili and Aphonchenko (1981), Lynn, Robinson, and Schwan (1985), and Ruth et al. (1982). There was virtually no difference between rarefaction and condensation clicks for wave III which is consistent to the results of Lynn et al. (1985) and Ruth et al. (1982). For wave V, condensation clicks yielded longer latency at the rate of 21.1 and 41.1 clicks/second.

The changes in amplitude and latency with rate did not depend upon stimulus polarity. Our results show no interaction of rate and polarity. Therefore, this would suggest that the reasons for the discrepant results among studies of the effects of stimulus polarity are not due to different stimulus rates employed in these studies. It would further suggest that some other variable is interacting with polarity such as electrode configuration, instrumentation, and stimulus parameters (i.e., intensity, spectral content). Salt (1982) reported that "the acoustic properties of the ear canal actually reversed the polarity at the eardrum in $40 \%$ of subjects" (p. 380). In other words, the condensation click turned into a rarefaction click at the eardrum. The only way 
to determine if this is happening is to use an ear canal probe microphone to check the polarity at the eardrum. It can be concluded that the components of the ABR may be greatly influenced by the stimulus polarity, however the effects are not uniform. Further research is needed to determine the effect of polarity on the ABR. Additional investigation into the role that ear canal acoustics has on the polarity presented to the tympanic membrane is necessary. Larger number of subjects in a study may also clarify the effects of polarity. Since there are rate effects and possible polarity effects on the $A B R$, it is recommended that each clinic generate its own normative data for the rate and polarity it chooses to routinely employ. 


\section{REFERENCES}

Bergholtz, L. (1981). Normative data in clinical auditory brainstem response. Scandinavian Audiology, Supp. 13: 75-81.

Borg, E. and Lofquist, L. (1982). Auditory brainstem response to rarefaction and condensation clicks in normal and abnormal ears. Scandinavian Audiology, 11: $227-235$.

Emerson, R., Brooks, E., Parker, S., and Chiappa, K. (1982). Effects of clicks polarity brainstem evoked potentials in normals and patients: unexpected sensitivity of wave V. Annals of New York Academy of Science, 388: $710-721$.

Fowler, C. and Noffsinger, D. (1983). Effects of stimulus repetition rate and frequency on the ABR in normal, cochlear-impaired and VIII nerve brainstem-impaired subjects. Journal of Speech and Hearing Research, 26 : 560-567.

Gerling, I. and Finitzo-Hieber, T. (1983). ABR with high stimulus rates in normal and patient populations. Annals of Otology, Rhinology, and Laryngology, 92(2): $119-123$.

Glattke, T. (1983). Short-latency auditory evoked potentials. Baltimore: University Park Press.

Hal1, J. W. (1984). Auditory brainstem response audiometry. In J. Jerger (ed.), Hearing disorders in adults.

San Diego: College-Hill Press.

Jacobsen, J. T., ed. (1985). The auditory brainstem response. San Diego: College-Hill Press.

Jacobsen, J. and Hyde, M. (1985). An introduction to auditory evoked potentials. In J. Katz (ed.), Handbook of clinical audiology. Baltimore: Williams and Wilkins.

Jewett, D. L. and Williston, J. S. (1971). Auditory-evoked far fields averaged from the scalp of humans. Brain, $94: 681-696$.

Kevanishvili, Z. and Aphonchenko, V. (1981). Click polarity inversion effects upon the human brainstem auditory potential. Scandinavian Audiology, 10:141-147. 
Lasky, R. (1984). A developmental study on the effect of stimulus rate on the auditory evoked brainstem response. Electroencephalography and Clinical Neurophysiology, 59:411-419.

Lynn, G., Robinson, D., and Schwan, S. (1985). ABR stimulus polarity effects in brainstem disease. Paper presented at the American Speech and Hearing Association convention, Chicago, IL.

Maurer, K., Schafer, E., and Leitner, H. (1980). The effect of varying stimulus polarity on early auditory evoked potentials. Electroencephalography and Clinical Neurophysiology, 50:332-334.

Møller, A. and Jannetta, P. J. (1985). Neural generators of the auditory brainstem response. In J. T. Jacobsen (ed.), The auditory brainstem response. San Diego: College-Hill Press.

Ornitz, E., Mo, A., Olson, S., and Walter, D. (1980). Influence of click sound pressure direction on brainstem responses in children. Audiology, 19:245-254.

Paludetti, G., Maurizi, M., and Ottaviani, F. (1983). Effects of stimulus repetition rate on the auditory brainstem response. American Journal of Otology, 4(3):226-234.

Robinson, D., Lynn, G., and Schwan, S. (1985). ABR stimulus polarity: a recommended calibration procedure. Paper presented at the American Speech and Hearing Association convention, Chicago, IL.

Rowe, M. J. (1978). Normal variability of the brainstem auditory evoked response in young and old adult subjects. Electroencephalography and Clinical Neurophysiology, $44: 459-470$.

(1981). Brainstem auditory evoked response in neurological disease: a review. Ear and Hearing, 2:41-51.

Ruth, R., Hildebrand, D., and Cantrell, R. (1982). A study of methods used to enhance wave $I$ in the auditory brainstem response. Otolaryngol. Head Neck Surgery, 90:635-640.

Salt, A. (1982). Auditory brainstem response testing strategies. Cited by J. Jerger, T. Oliver, and B. Stach in J. T. Jacobsen (ed.) (1985), The auditory brainstem response, chap. 20. San Diego: College-Hill Press.

Stockard, J. J., Stockard, J. E., and Sharbrough, F. W. (1978). Nonpathologic factors influencing brainstem auditory evoked potentials. American Journal of EEG Technology, $18: 177-209$. 
Stockard, J. J., Stockard, J. E., Westmoreland, B. F., and Corfits, J. L. (1979). Brainstem auditory-evoked responses: normal variation as a function of stimulus and subject characteristics. Archives of Neurology, $36: 823-831$.

Tvete, O. and Haugsten, P. (1981). ABR in cat, latency as a function of stimulus polarity, intensity, and acoustic waveform. Scandinavian Audiology, Supp. 13:25-28. 
APPENDIX A

INTAKE INFORMATION 


\section{APPENDIX A}

\section{INTAKE INFORMATION}

Name : Identification no.

DOB : Evaluation date:

Present health:

Medical History

Yes No

Comments

head injury

neurological problems

seizures

ear problems

ear surgeries

accidents

present medications

noise exposure

Eamily History

hearing loss

seizures

neurological

problems or disease 
APPENDIX B

DATA SHEET 


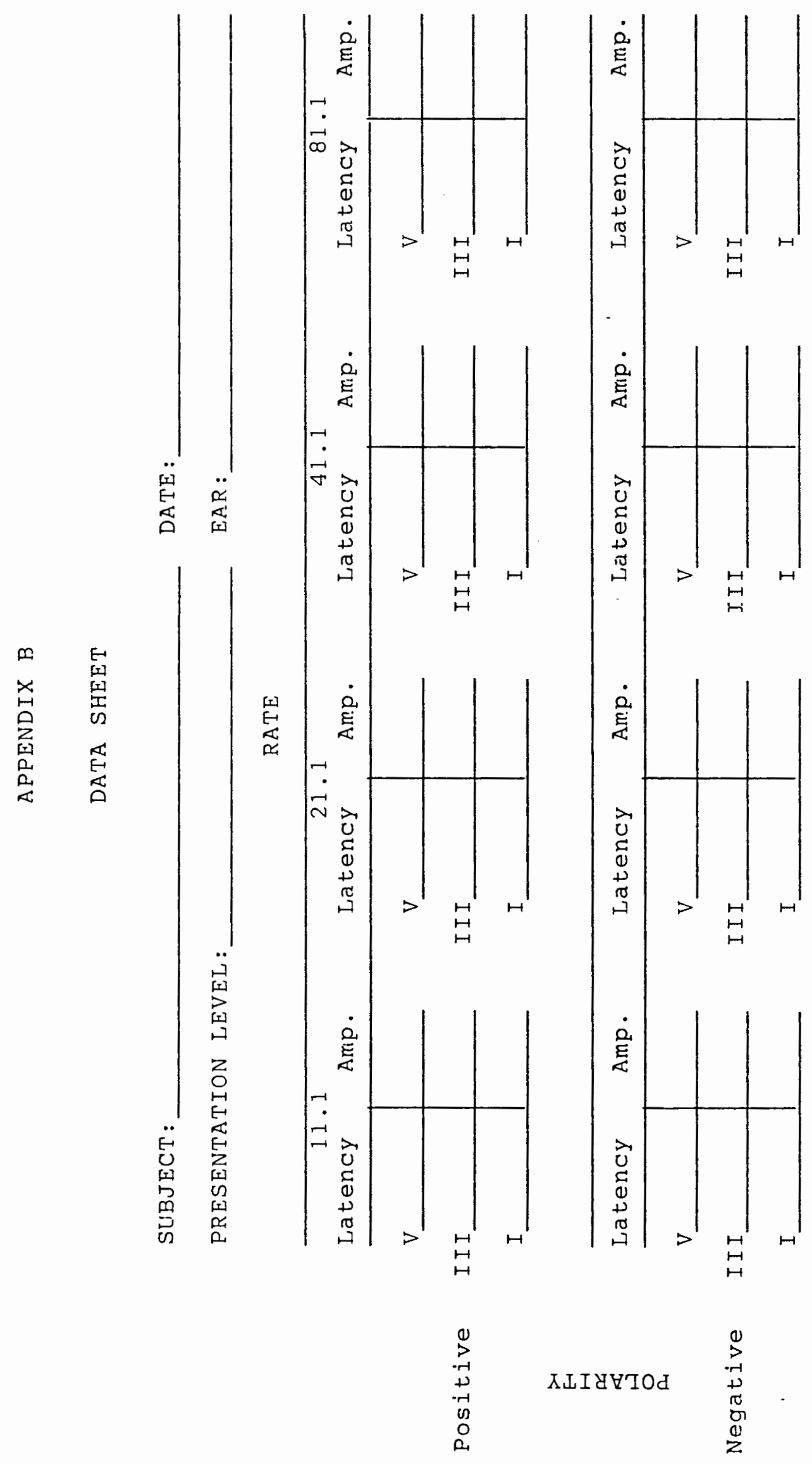


APPENDIX C

INEORMED CONSENT 
APPENDIX C

INFORMED CONSENT

\author{
OHSU \\ Crippled Children's Division \\ Auditory Brainstem Response:
}

The Interaction of Stimulus Rate and polarity on the Auditory System of Males

I, , consent to my/my child's participation in a study under the supervision of Rodney 0 . Pelson, Ph.D. and Michelle A. Ziegler, Audiology Intern, at the Crippled Children's Division, the Oregon Health Sciences University. The purpose of this study is to obtain normative data on a relatively unexplored area of Auditory Brainstem Response (ABR) testing. Electrical brain activity resulting from stimulating the auditory system with a broad band "click" stimulus will be recorded using electrodes glued to the forehead and behind each ear.

This procedure will require the participant to lie on a padded table while wearing earphones for approximately one hour. prior to this testing, the participant will be required to pass a preliminary audiometric test battery to insure normal peripheral hearing sensitivity. The preliminary test battery will take approximately one hour.

All testing will take place at Crippled Children's Division (CCD), the oregon Health Sciences University (OHSU), in one or two sessions. Participation is on a volunteer basis with no payments made or charges assessed to the participant. All participants attending school will be tested during nonschool hours. There is no physical, psychological or social risk inherent in participation in the research study described. The only possible slight discomfort is having the electrodes glued to the scalp. No medications will be used.

This study will provide me with a professional evaluation of my/my child's hearing status and will be made available to me and to medical records upon request. The information octained from the study will be useful to medical science in understanding a relatively unexplored area of ABR. I understand 
that all identifying information, including the participant's name, will be held confidential. Dr. Pelson and Mrs. Ziegler have offered to answer any questions I might have regarding the study, specifically the test procedures and the participant's involvement. I may contact them at CCD, OHSU (phone 225-8356). I also understand that the participant is under no obligation to complete the study, and that withdrawal from the study will not affect the participant's relationship or treatment at the oregon Health Sciences University.

The Oregon Health Sciences University as an agency of the State is covered by the state Liability Fund. If you suffer any injury from the research project, compensation would be available to you only if you establish that the injury occurred through the fault of the University, its officers or employees. If you have further questions, please call Dr. Michael Baird, M.D. at (503) 225-8014.

I agree to participate in the study. of age) 